\title{
Geospatial analysis of habitat use by silver hake Merluccius bilinearis in the Gulf of Maine
}

\author{
Jose J. Pereira ${ }^{1, *}$, Eric T. Schultz ${ }^{2}$, Peter J. Auster ${ }^{3}$ \\ ${ }^{1}$ NOAA Fisheries, Milford Laboratory, 212 Rogers Avenue, Milford, Connecticut 06460, USA \\ ${ }^{2}$ Dept. of Ecology and Evolutionary Biology, University of Connecticut, Storrs, Connecticut 06269-3043, USA \\ ${ }^{3}$ Department of Marine Sciences at the University of Connecticut, and Sea Research Foundation - Mystic Aquarium, Groton, \\ Connecticut 06340, USA
}

\begin{abstract}
Three theories of habitat use proposed for marine fishes, the constant density model $(\mathrm{CDM})$, the proportional density model (PDM), and the basin model (BM), make contrasting predictions of how the range, local density, and fitness change as population size changes. We tested model predictions using a survey of silver hake Merluccius bilinearis conducted by the National Marine Fisheries Service every spring and fall. Data on fish length, sex, weight, and reproductive status are collected. Despite a $50 \%$ population reduction over the time period of the survey, the geographic area occupied by silver hake did not change significantly. Local density in preferred habitat remained a constant proportion of the entire population. Fitness (as indicated by individual condition) varied over a fine spatial scale, reflected in a pattern of spatial autocorrelation of $10 \mathrm{~s}$ to 100s of kilometers. Fitness did not exhibit density dependence, except in one case, females in the fall, probably due to the higher energy needs of the females. The results indicate that silver hake conform to the PDM, a site-dependent model, and yet we found some evidence of density dependence in our measure of fitness. Site dependence may work in concert with density dependence to regulate population size. Sites silver hake depend on may be the spawning areas along the coast, which may already be in legislatively protected areas. Our study illustrates that an understanding of habitat use is important for crafting conservation or management measures that lead to maintenance of a stable population.
\end{abstract}

KEY WORDS: Spatial autocorrelation $\cdot$ Kriging $\cdot$ Silver hake $\cdot$ Gulf of Maine $\cdot$ Habitat

\section{INTRODUCTION}

Changes in abundance, as a result of population depletion or recovery, may have an effect on habitat use and geographical distribution. Petitgas (1998) identified 3 theoretical constructs which have been used to describe the relationship between the abundance and distribution of marine fishes, the constant density model (CDM), the proportional density model (PDM) and the basin model (BM). The CDM predicts that local density remains constant and that the range (geographical area occupied by the species) expands and contracts with changes in popula- tion size. The PDM predicts that the range occupied remains constant and that local population density is a constant proportion of the whole. The BM predicts that both the range and local population density change in response to global changes in population size. The CDM and PDM propose a site-dependent mechanism driving the observed patterns of habitat use, while the BM proposes density dependence as the driving force. For a more complete discussion of these 3 models, see Pereira et al. (2012).

The mechanism driving the CDM could be territoriality (Hilborn \& Walters 1992) or, more generally, site dependence (Rodenhouse et al. 1997). An indi- 
vidual claims exclusive access to some site (portion of habitat), and their presence precludes use by other individuals. Their presence does not degrade the habitat quality of adjacent areas, and more habitat is occupied as the population grows (Rodenhouse et al. 1997). Habitat quality, which is not affected by population size, is the sole determinant of reproductive success (McPeek et al. 2001). Site dependence in this case predicts that fitness is greater in higher quality habitat, which is occupied preferentially (Rodenhouse et al. 1997). Territoriality can be seen as a special case of site dependence in which dominant individuals actively exclude subordinates, but individual reproductive success is still determined by habitat quality. This is also equivalent to the ideal dominance model proposed by Fretwell \& Lucas (1969).

Myers \& Stokes (1989) claimed that the PDM explained North Sea haddock and American plaice distributions on the Grand Banks of Newfoundland, Canada, but proposed no mechanism to account for it. Increases in local density in phase with changes in global population could result from processes that provide site-specific enhancement of prey resources (Petitgas 1998). Patchy distribution of predator refuges could result in spatial heterogeneity in postsettlement survival of juveniles (Levin 1994) and would also provide an ecological mechanism for proportional changes in local abundance in the context of site-dependent habitat use. No predictions regarding fitness were made in the original description of the PDM. If site dependence is the basis for the PDM as discussed above, then differences in fitness should be detectable among habitats as in the CDM.

In the BM, MacCall (1990) proposed density dependent habitat use as the mechanism leading to changes in both range and local population density. Fretwell \& Lucas (1969) theorized that habitat suitability or fitness value is inversely related to population density. Hence, habitat use is density dependent, and an optimizing individual will leave initially highquality habitat when high abundance there has depressed fitness below that which can be obtained in a lower quality but less crowded habitat. Fretwell \& Lucas (1969) referred to this scenario as the ideal free distribution.

Identifying habitats and determining their relative utility to the organism is not a straightforward proposition. Individuals of a population are sometimes found in suboptimal habitats (Pulliam 1988, Pulliam \& Danielson 1991, Delibes et al. 2001, Kristan 2003, Schultz \& Ludwig 2005), and their presence does not indicate a sustainable population. Physical factors such as temperature, substrate and, in the case of marine fish, water depth and salinity may not explain their presence there. They may also be biased by our imperfect understanding of the organism's preference for some combination of these factors. Organisms in suboptimal habitats may need to allocate more energy for survival purposes, rather than for growth and reproduction. This is generally referred to as a fitness benefit. A proxy for fitness can integrate the interaction of all the environmental factors into a single variable that measures the organism's response to the habitat, making the modeling more straightforward. The organism's fitness is a measure of habitat quality which can differentiate among all the habitats occupied. Shepherd \& Litvak (2004) suggest a way forward for combining a spatially explicit model with one that also considers habitat quality by incorporating analyses of spatial variation of fitness in tests of density-dependent habitat use.

The relationship between density, distribution and fitness has recently been assessed for a benthic fish, but has not yet been assessed for a semi-pelagic fish. In a previous study (Pereira et al. 2012), we combined the suggestion of Shepherd \& Litvak (2004) with the 3 constructs of habitat use identified by Petitgas (1998) to examine a population of yellowtail flounder Limanda ferruginea on the northeast coast of the United States. The combination resulted in the predictions summarized in Table 1. We propose here to test these same predictions with data on silver hake

Table 1. Model predictions of changes in distribution and fitness with population size (N). Geographical range is the total area occupied by the species. Local density is the catch per unit effort within a given area. Local fitness is a measure of fish health generated from length and weight of individual fishes. Spatiotemporal variation in fitness is the predicted reaction of the fitness metric to changes in population size. CDM: constant density model; PDM: proportional density model; BM: basin model.

Taken from Pereira et al. (2012)

\begin{tabular}{|lllll|}
\hline Model & Geographical range & Local density & Local fitness & Spatiotemporal variation in fitness \\
\hline CDM & Increases with N & Constant over N & Constant over N & Spatial variance at high N \\
PDM & Constant over N & Constant proportion of N & Constant over N & $\begin{array}{l}\text { Spatial variance at high N } \\
\text { BM }\end{array}$ \\
Increases with N & Increases with N & Decreases with N & No change in spatial variance with N \\
\hline
\end{tabular}


Merluccius bilinearis from the Gulf of Maine. We chose to do a geospatial analysis of silver hake because it occupies a different trophic guild than yellowtail flounder. Yellowtail flounder prey exclusively on invertebrate, benthic prey items (Garrison \& Link 2000). While the diet of smaller silver hake is also made up primarily of invertebrates (Bowman \& Bowman 1980), the larger animals, particularly at night, move higher up in the water column, feeding on fish, squid, euphausiids, and other pelagic crustaceans (Garrison \& Link 2000).

\section{MATERIALS AND METHODS}

The data for this study was collected by biannual bottom trawl survey of the northeast continental shelf which has been conducted by the National Marine Fisheries Service since 1963. Originally designed to monitor changes in the abundance of economically important marine species, the survey now monitors the entire ecosystem, including species that are not economically important (Grosslein 1969). The survey area encompasses the continental shelf from Canadian waters near Nova Scotia southward to Cape Hatteras, North Carolina, USA (Fig. 1). Sampling stations are chosen randomly each year within strata that are defined by depth and temperature. The number of stations are proportional to stratum area (Grosslein 1969, Azarovitz 1981), and so the average catch per unit effort (CPUE) is in fact a weighted average. With the exception of the shallow central areas of Georges Bank, the minimum number of stations in a stratum is 2 . Between 350 and 400 stations are typically sampled on a survey, approximately 1 for each 200 square nautical miles. We used 2 types of data from the survey. (1) Total catch data is the weight or number of individuals caught at a given station and does not separate individuals by sex. (2) Biological data is randomly sampled from the total catch data, but includes weights and lengths of individual fish, as well as their sex and the state of gonadal development (maturity). Data collected are corrected for changes in survey vessel and equipment changes over the years. Standardized tows are conducted for $30 \mathrm{~min}$, during which the ship covers about 1.5 nautical miles. For each tow, environmental data (water temperature, depth, salinity) are collected, and the catches are sorted by species, counted, and a subsample is weighed and measured. CPUE is estimated as catch (kg) per tow.

Silver hake Merluccius bilinearis is managed as 2 stocks, based on the morphometric analysis done by Almeida (1987). The northern population occupies

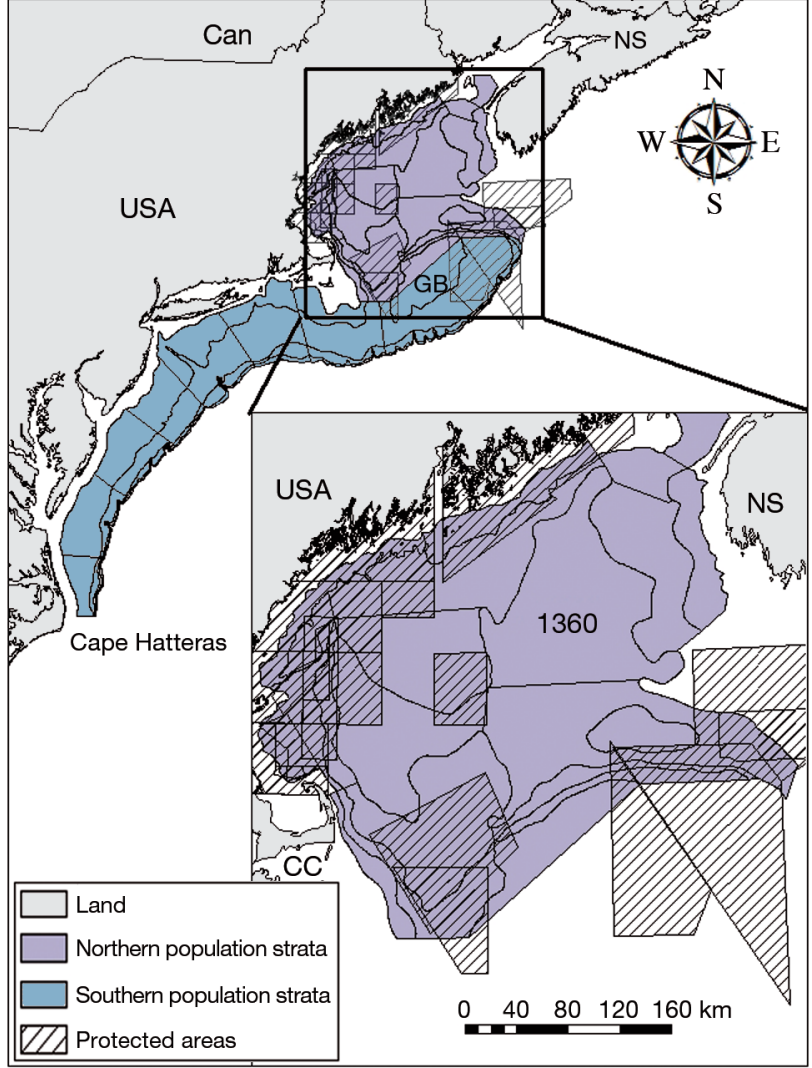

Fig. 1. Study area on the east coast of the United States showing the location of Cape Cod, Massachusetts, USA (CC) and Nova Scotia, Canada (NS), Georges Bank (GB), and Canada (Can). The location of Sampling Stratum 1360 is also shown

the Gulf of Maine from Nova Scotia to Cape Cod, Massachusetts and eastward to the northern edge of Georges Bank. The southern population extends from the southern flank of Georges Bank southward to Cape Hatteras. The shallow areas in the middle of Georges Bank serve as a buffer between the 2 populations (Fig. 1).

To test predictions regarding the effect of abundance on geographical range, we chose data from the highest (1998 to 2000) and lowest (2004 to 2006) population periods in the available data (see Fig. 2). We used geospatial tools to estimate the geographic area occupied by the silver hake population each year. Individual catch records were plotted using a geographic coordinate system (North American Datum [NAD] 1983), using the latitude and longitude where each trawl began. Coordinates were then reprojected into Universal Transverse Mercator (UTM; NAD 1983, Zone 19N) to permit accurate measurements of distances, geospatial relationships and areas occupied. 
Kriging was used to interpolate between sampling stations and convert the point data (catch weight at a location) to a continuous surface (area) representing the distribution of the catch data. We used a cross validation and regression procedure (ESRI 2001, Pereira et al. 2012) to check the validity of the kriging model. We regressed values predicted by kriging against those that were measured. A significant regression was taken as evidence of spatial autocorrelation in the data and, along with the r-square value, helps to validate the predictive value of the kriging. We used the log-transformed total weight of silver hake caught at each sampling station, because the untransformed data resulted in models that were not significant. The kriging map was exported as vector coverage (polygons with associated areas). These filled contours were then used, in turn, to select the survey sampling stations that they contained to calculate the cumulative survey catch sampled at those stations. Once the cumulative catch weight approached, but did not exceed, $100 \%$ of the total survey catch weight sampled, the cumulative area of those contours was deemed to be the geographical area occupied. Since kriging interpolates between sample stations to create the continuous surface, some contours extended beyond the sample area, some even reaching land areas, and resulted in areas of occupancy that exceeded the actual sampling area. We, therefore, used the northern population strata to 'clip' (ESRI 2006) the vector coverage produced from the kriging surface to produce more realistic areas of occupancy for silver hake. Differences in mean areas occupied during high (1998 to 2000) versus low (2004 to 2006) abundance periods were tested via 2-sample $t$-test. For tests of other predictions (see Table 1), we used the data from a longer time series (1992 to 2008), beginning when data on individual fish weights were added to the quantification of catch.

Predictions regarding local density were tested by comparing localized population densities within a high-quality habitat (Stratum 1360) to those in the northern population strata as a whole. Since total catch weights have been recorded since the beginning of the survey, we were able to use the time period from 1986 to 2008 to compare catches among strata. Compared to the rest of the survey strata defining the northern population, Stratum 1360 had the highest catches of silver hake in the survey, ranking first in total biomass and second in our CPUE calculations for the fall data. This stratum contains finer grained substrates (Methratta \& Link 2006) and prey items such as euphausiids and pandalids (Garrison \&
Link 2000) that make up a significant portion of the silver hake diet. The total survey catch from Stratum 1360 for each year was expressed as a percentage of the catch from the northern population as a whole, and the relationship between the catch in Stratum 1360 and the total catch in the northern strata was tested via regression. This was done for both fall and spring survey data. We also compared CPUE in Stratum 1360 to that in the rest of the northern strata. We calculated a CPUE for Stratum 1360 and for the northern strata as a whole by dividing the biomass of silver hake captured in the survey each year by the total number of tows in that year. The CPUE serves as a measure of fish density and also serves as a measure of relative abundance of the population. We used data from 1986 to 2008, since individual fish weights were not needed, only the total weight of the catch.

We used a condition index expressing relative fish mass to test model predictions regarding spatial heterogeneity in fitness. While fish lengths have been routinely collected since the beginning of the National Marine Fisheries Service (NMFS) survey, individual fish weights have only been available since 1992 . Long used in various forms as a measure of health or condition, the relationship between mass and length in fishes (Le Cren 1951) is an indicator of the energy available for reproduction (Burton \& Idler 1984, Burton 1994). We used the residual mass index described in Jakob et al. (1996), which determines each individual's deviation from a regression based on a logweight to log-length relationship. Prior to the regression analysis, the mass-length data was parsed into groups based on season, sex, and gonadal development. Length-weight relationships are likely to be different in spring and fall because of gonadal development during the spawning season. Mature ovaries can comprise up to $14 \%$ or more of a female silver hake's mass (Wilk et al. 1990), so only fish of the same maturity stage were used for the analysis for each season to minimize the variability in our analysis (Pereira et al. 2012).

Each fish was classified upon capture as immature, developing, ripe, spent, resting, or unknown (Morse 1979) . Silver hake have a protracted spawning season with ripe females taken in nets from March through October, although mean gonadosomatic indices (GSI) are highest from July to October (Wilk et al. 1990). Fish in any given sample can, therefore, vary among many different maturity classifications. We chose resting fish from both the spring and fall surveys to avoid the higher variance that would result from including individuals with developing gonads. Females outnumbered males in our data. 
Since silver hake are known to be cannibalistic, we compared mean lengths of males and females via a $t$ test (SAS 2010) to explore the possibility that females were significantly larger than males and might be cannibalizing them causing the sex bias.

We analyzed spatial variability in condition with 2 different methods. The first was a nested mixedmodel analysis of variance (ANOVA) among sampling strata. The main effects in this model were abundance (2 levels: low and high), stratum (20 levels), season (fall and spring), and year (random effect nested within each combination of abundance, stratum, and season). We used the mean square error (MSE) of the nested effect in the denominator for F-tests of each interaction and the main effect. Sexes were analyzed separately. The second method was a geospatial analysis of variation in our proxy for fitness, the logmass residuals (Jakob et al. 1996) conducted and calculated separately for each combination of sex, season, and abundance. We constructed a prediction surface using kriging or cokriging from the fitness data. A description of the kriging process can be found in Appendix I in Pereira et al. (2012). We regressed the predicted fitness values against the observed fitness values and accepted a significant outcome as evidence of spatial autocorrelation. We refer to the range of the semivariogram as the autocorrelation distance (ACD), so as not to confuse it with the geographical range of the population.

\section{RESULTS}

The geographic area occupied by the northern population of silver hake Merluccius bilinearis was not significantly affected by abundance. In the fall, the area occupied was $69292 \mathrm{~km}^{2}$ during the low population period (2004 to 2006) and $75692 \mathrm{~km}^{2}$ during the high population period (1998 to 2000, $\mathrm{n}=3, \mathrm{p}=0.14$ ). During the spring, areas occupied by silver hake were $69167 \mathrm{~km}^{2}$ when populations were low and $76411 \mathrm{~km}^{2}$ when they were high $(n=3, p=0.38)$. Northern population abundance was generally higher in the fall than in the spring survey (Fig. 2). Abundance in high-quality habitat in the fall followed similar trends to regionwide abundance but was much more variable. Abundance in the high-quality habitat in the spring was similar to the region-wide abundance (Fig. 2). Fall biomass in high-quality habitat, expressed as a percent of the total biomass surveyed, did not change significantly with changes in overall abundance (Fig. 3; $p=0.39$ ). The same was true of the spring survey data (Fig. $4 ; \mathrm{p}=0.11$ )
Condition over the geographic range did not change significantly among females or males in either season as abundance changed (Table 2). However, condition was inversely related to abundance in resting females in the fall in Stratum 1360 (Table 3). We did not see this response in males or females in the spring or in males in the fall (Table 3).

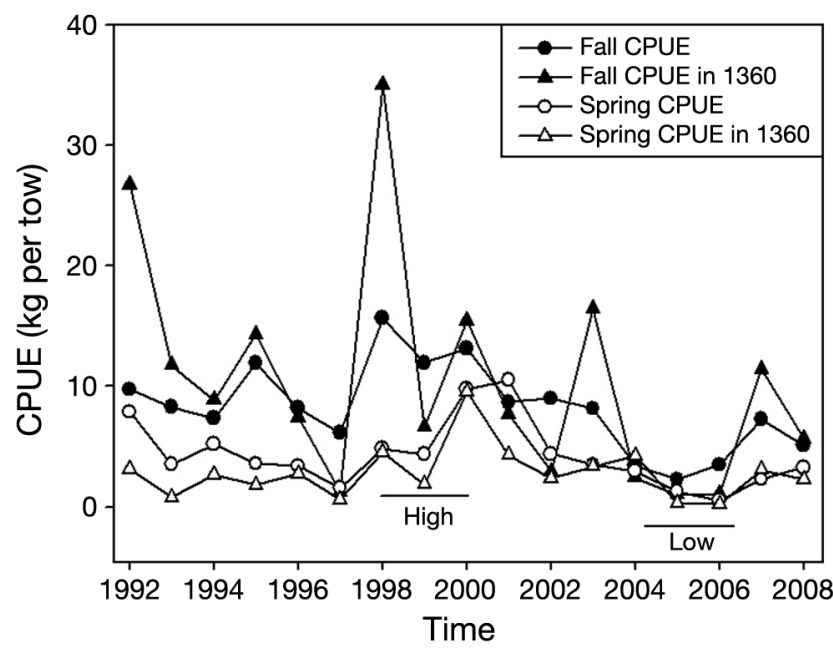

Fig. 2. Merluccius bilinearis. Abundance (indicated as catch per unit effort, CPUE) of the northern population of silver hake. Horizontal bars indicate high and low population years

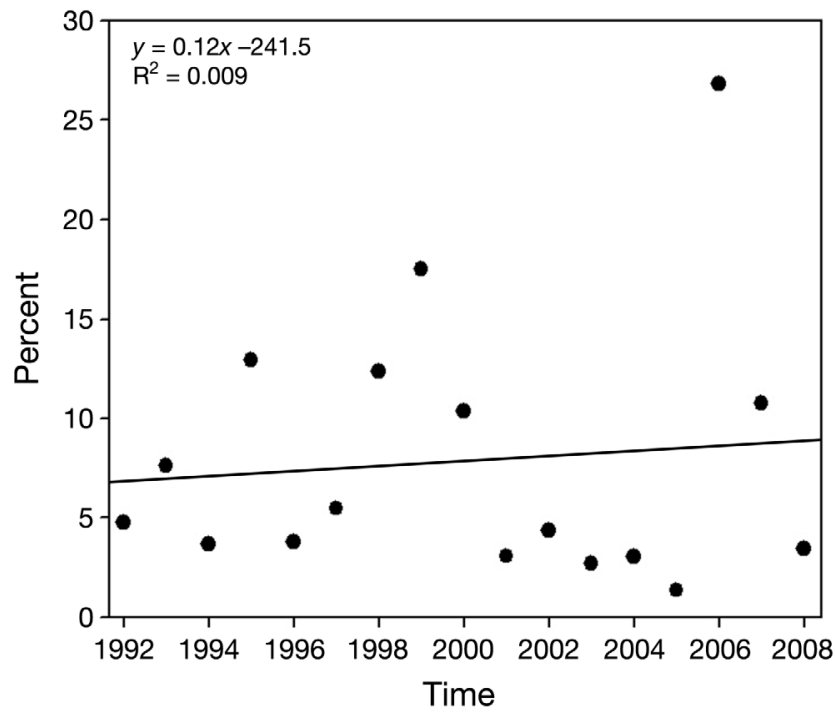

Fig. 3. Merluccius bilinearis. Population (biomass in kg) of silver hake in Sampling Stratum 1360 in the fall, expressed as a percentage of the northern population biomass in the fall. The slope of the regression line is not significantly different from zero $(p=0.72)$. Data include both males and females 


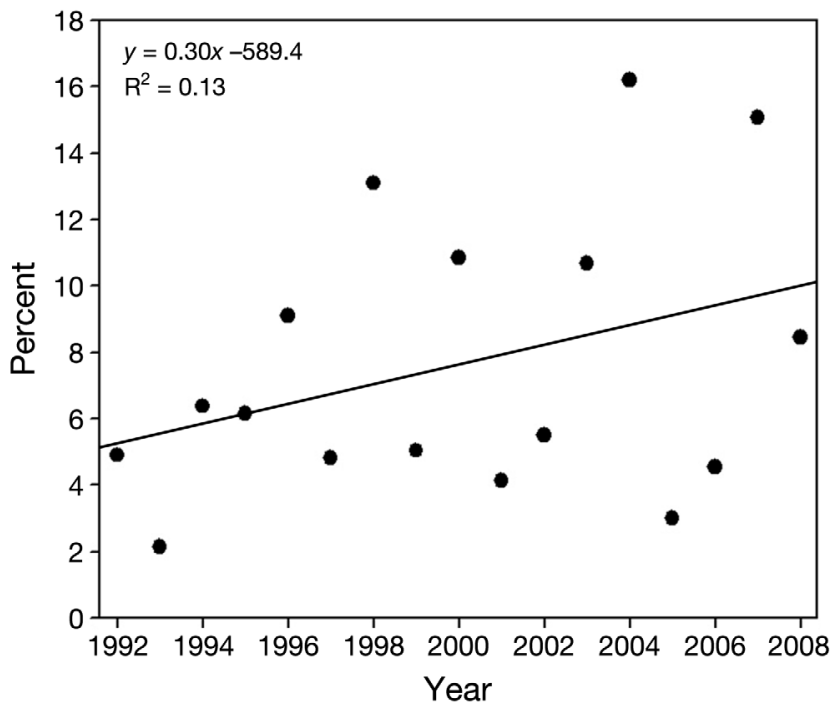

Fig. 4. Merluccius bilinearis. Population (biomass in kg) of silver hake in Sampling Stratum 1360 in the spring, expressed as a percentage of the northern population biomass in the spring. The slope of the regression line is not significantly different from zero $(p=0.17)$. Data include both males and females

Table 2. Merluccius bilinearis. Regression of yearly mean log-mass residuals against the yearly catch per unit effort for the northern population of silver hake. All fish were at the resting stage of gonadal development

\begin{tabular}{|lllc|}
\hline Sex & Equation & $\mathrm{r}^{2}$ & $\mathrm{p}$ \\
\hline Spring & & & \\
Males & $y=-0.0026 x-0.0111$ & 0.1201 & 0.19 \\
Females & $y=-0.0014 x-0.0157$ & 0.052 & 0.38 \\
Fall & & & \\
Males & $y=-0.0002 x+0.0186$ & 0.0018 & 0.88 \\
Females & $y=-0.0011 x+0.0229$ & 0.0735 & 0.29 \\
\hline
\end{tabular}

Table 3. Merluccius bilinearis. Regression of yearly mean log-mass residuals in Stratum 1360 against the yearly catch per unit effort for the northern population of silver hake. All fish were at the resting stage of gonadal development

\begin{tabular}{|llcc|}
\hline Sex & Equation & $\mathrm{r}^{2}$ & $\mathrm{p}$ \\
\hline Spring & & & \\
Males & $y=-0.0039 x-0.0138$ & 0.110 & 0.25 \\
Females & $y=-0.0003 x-0.0165$ & 0.001 & 0.91 \\
Fall & & & \\
Males & $y=-0.0019 x+0.0361$ & 0.169 & 0.11 \\
Females & $y=-0.0026 x+0.0449$ & 0.320 & 0.02 \\
\hline
\end{tabular}

Condition differed by season, but not by quality of habitat, on the scale of sampling strata. ANOVA showed that only season influenced our measure of fitness (ANOVA, $p=0.001$ ). Among resting females, the mean log-mass residual was 0.012796 in the fall $(\mathrm{n}=1024)$ and -0.016061 in the spring $(\mathrm{n}=387)$. The model accounted for $32 \%$ of the variation in log-mass residuals. Condition indices among sampling strata were not significantly different.

Geospatial analysis revealed variability in condition at a spatial scale finer than sampling strata in all cases save one. Results of the geospatial analysis are shown in Table 4. Males in the fall, during the high population period, showed a maximum ACD of $360 \mathrm{~km}$ (Table 4). For females, ordinary kriging gave the best results in both spring and fall when populations were high, while cokriging with depth as the cofactor gave better results at low population levels. Females showed spatial heterogeneity in fitness in both spring and fall and at both high and low population levels. The spatial model accounted for as much as $27 \%$ of the variation in the log-mass residuals. ACDs varied from 20 to $100 \mathrm{~km}$. Males showed significant spatial heterogeneity in fitness only when populations were high (Table 4). The models accounted for 0.09 (fall) and 0.24 (spring) of the variation in the log-mass residuals.

Mean lengths of male and female silver hake were significantly different in spring and fall, and females outnumbered males by approximately 2 to 1 (Table 5).

\section{DISCUSSION}

Our results support the PDM of dynamics in habitat use (Table 1). The PDM has also been used to explain North Sea haddock and American plaice distributions on the Grand Banks of Newfoundland (Myers \& Stokes 1989), both benthic species. Pereira et al. (2012) suggested that site dependence was the mechanism that drives the PDM, which is what you might expect from a benthic species. It was unexpected to see the PDM apply here to a species that spends a significant amount of time up in the water column (Bowman \& Bowman 1980). Atlantic herring Clupea harengus is a species that feeds exclusively in the water column (on zooplankton), and yet it is a site-dependent species because population size is dependent on the size of larval retention areas and spawning sites for the herring's demersal eggs (Iles \& Sinclair 1982).

The geographical range occupied by silver hake Merluccius bilinearis did not change with population size. Local population density in Stratum 1360 remained a constant proportion of the entire population (Fig. 3). This is consistent with the PDM. Abundance in Stratum 1360 was much more variable than 
Table 4. Merluccius bilinearis. Results of geospatial analysis of the log-mass residuals during high (1998 to 2000) and low (2004 to 2006) population levels showing autocorrelation distance (ACD) and partial sill. Slope, p-values, and $\mathrm{R}^{2}$ are from regression of measured versus values predicted from kriging. Significant values indicated in boldface

\begin{tabular}{|lccccccc|}
\hline Season & Population & ACD $(\mathrm{km})$ & Partial sill & Slope & $\mathrm{p}$ & $\mathrm{R}^{2}$ & $\mathrm{~N}$ \\
\hline Females & & & & & & & \\
Fall & High & 79 & 0.00097 & 0.217 & $\mathbf{< 0 . 0 1}$ & 0.27 & 717 \\
Fall & Low & 20 & 0.00048 & 0.148 & $<\mathbf{0 . 0 1}$ & 0.15 & 291 \\
Spring & High & 37 & 0.00083 & 0.108 & $\mathbf{< 0 . 0 1}$ & 0.12 & 219 \\
Spring & Low & 100 & 0.00054 & 0.056 & $\mathbf{0 . 0 2}$ & 0.04 & 135 \\
Males & & & & & & & \\
Fall & High & 360 & 0.00069 & 0.093 & $<\mathbf{0 . 0 1}$ & 0.09 & 339 \\
Fall & Low & 56 & 0.00000 & 0.004 & 0.76 & 0.0005 & 197 \\
Spring & High & 64 & 0.00050 & 0.224 & $<\mathbf{0 . 0 1}$ & 0.24 & 98 \\
Spring & Low & 11 & 0.00935 & 0.082 & 0.06 & 0.03 & 106 \\
\hline
\end{tabular}

Table 5. Merluccius bilinearis. Comparison of mean male and female lengths via Student's $t$-test. All individuals were at the resting stage of gonadal development

\begin{tabular}{|llccccc|}
\hline Season & $\begin{array}{c}\text { Females } \\
(\mathrm{cm}, \pm \mathrm{SD})\end{array}$ & $\mathrm{n}$ & $\begin{array}{c}\text { Males } \\
(\mathrm{cm}, \pm \mathrm{SD})\end{array}$ & $\mathrm{n}$ & Sex ratio & $\mathrm{p}$ \\
\hline Fall & $29.7 \pm 5.07$ & 1024 & $25.5 \pm 3.0$ & 560 & 1.83 & 0.0001 \\
Spring & $26.8 \pm 5.2$ & 387 & $23.7 \pm 3.1$ & 209 & 1.85 & 0.0001 \\
\hline
\end{tabular}

it was in the population as a whole (Fig. 2), probably due to the fact that it is always open to commercial fishing. Migration in and out of the stratum could also be a factor. Estimating geographic range from point occurrences requires interpolation of densities or additional data on individual home range behavior. In a previous study (Pereira et al. 2012) we used a kernel density estimator to assess the geographical area occupied by yellowtail flounder Limanda ferruginea. The kernel density estimator calculates fish density within a circular surface around a point based on a selected search radius and the number of fish caught there. We used $20 \mathrm{~km}$ for our search radius, based on known yellowtail migration distances from tagging studies. There is very little tagging information for silver hake (Fritz 1959, 1963), and it focuses on how the tags are returned (from which fishery or processing plant) rather than on the distances traveled between release and recapture points. The lack of tagging data forced us to use the kriging surface as our estimate of the geographical area occupied. We do not know whether these 2 methods yield comparable results.

The PDM predicts that local fitness does not change with global changes in abundance, because fitness is related to site and not population size. In our analysis, fitness did not change with population size when considering the northern population as a whole (Table 2). When we compared abundance of the northern population to fitness in Stratum 1360, only females in the fall showed a negative relationship (Table 3). This stratum had the highest total biomass collected over the duration of the survey and ranked second in mean CPUE. It is likely that abundance became so high in this stratum that carrying capacity was reached or exceeded and density dependence caused the reduction in fitness that we observed. Site dependence must have a limit. In addition, females have higher energy requirements than males and having recently spawned (Lock \& Packer 2004) were in the process of regaining the energy lost as eggs.

Spatial heterogeneity in fitness was observed in all of our analyses save 2, i.e. the males when population levels were low in the spring and the fall (Table 4). This is also in keeping with the PDM, which predicts spatial variation in fitness at high population levels (Table 1). Females showed spatial heterogeneity in fitness even when populations were low (Table 3). Females are less likely to obtain all the food they need because of the high cost of making lipid-rich eggs. This may have led to the spatial heterogeneity in fitness that we observed, even at low abundances.

The female sex ratio bias we observed in our data has been observed elsewhere (Wilk et al. 1976, Lock \& Packer 2004); $70 \%$ of silver hake age 5 or older are females (Lock \& Packer 2004). Females are larger at age than males and consume twice as many fish, by weight. Cannibalism is common in silver hake (Koeller et al. 1989, Garrison \& Link 2000, Tsou \& Collie 2001, Link et al. 2012), and, given the size difference between the sexes (Table 5), it is likely that males are routinely preyed upon by females. Because of their smaller size, males may also be preferentially taken by predators other than the females.

Our findings for the silver hake contrast with our findings for benthic yellowtail flounder (Pereira et al. 2012), where we found strong support for the BM, support for some aspects of the CDM, and no support for the PDM. The geographic range occupied by yellowtail flounder increased significantly when abundance increased, whereas we saw no increase with silver hake. Abundance in the preferred habitat of 
yellowtail flounder continued to increase even as abundance in the surrounding area decreased or stayed the same (Pereira et al. 2012). The proportion of silver hake in their preferred habitat was a constant proportion of the whole (Figs. 3 \& 4). Yellowtail flounder had a very definite preferred habitat on Georges Bank, which was enhanced by being included in a protected area (Pereira et al. 2012). The preferred habitat of silver hake seems to be more widespread; there were multiple strata that seemed to hold large populations of silver hake.

Similar to Pereira et al. (2012), however, we found a combination of site-dependent and density-dependent forces shaping the distribution of silver hake. We did detect density dependence in female silver hake in the fall, when in Stratum 1360 we saw the log-mass residuals decrease when populations were high (Table 3). Even a good site has a carrying capacity which can be exceeded.

Our findings have consequences for both management and conservation, since both have at least one goal in common. Conservation seeks to maintain a sustainable population to prevent loss of species, to increase diversity, and to stabilize ecosystems. This is especially true of endangered species. Management also seeks to maintain a sustainable population with the added goal of harvesting some portion of that population for consumption. In either case an understanding of habitat use is important for crafting conservation or management measures that lead to maintenance of a stable population.

Silver hake show a site-dependent pattern of habitat use (the PDM). It would be important to identify and protect those sites on which they are dependent. Like Atlantic herring, they may be dependent on spawning and larval retention areas. Silver hake have been reported to spawn along the coast of the Gulf of Maine from Cape Cod northwards and along the southeastern flank of Georges Bank (Lock \& Packer 2004). They may benefit from protected areas already in place there (Fig. 1).

Our approach here detected small-scale heterogeneity in fitness that was not detected by analysis of variance among sampling strata. Most of the ACD values in Table 4 are relatively small compared to the scale of the Gulf of Maine and indicate this fine variability. The sampling strata are constructs based on depth and, to some degree, bottom substrate, and we assume on a broad scale that habitat within these strata is similar. The geospatial approach makes no assumptions about what the organisms prefer, but rather looks at the response of the organism as a clue to when the habitat changes.
Acknowledgements. We thank William Kramer of the National Marine Fisheries Service laboratory in Woods Hole, Massachusetts, USA, for providing the data used in this study from the trawl survey database.

\section{LITERATURE CITED}

Almeida FP (1987) Stock definition of silver hake in the New England-Middle Atlantic area. N Am J Fish Manag 7: 169-186

Azarovitz T (1981) A brief historical review of the Woods Hole Laboratory trawl survey time series. Publ Spec Can Sci Halieut Aquat 58:62-67

Bowman RE, Bowman EW (1980) Diurnal variation in the feeding intensity and catchability of silver hake (Merluccius bilinearis). Can J Fish Aquat Sci 37:1565-1572

Burton MPM (1994) A critical period for nutritional control of early gametogenesis in female winter flounder, Pleuronectes americanus (Pisces: Teleostei). J Zool (Lond) 233:405-415

> Burton MP, Idler DR (1984) The reproductive cycle in winter flounder, Pseudopleuronectes americanus (Walbaum). Can J Zool 62:2563-2567

> Delibes M, Gaona P, Ferreras P (2001) Effects of an attractive sink leading into maladaptive habitat selection. Am Nat 158:277-285

ESRI (Environmental Systems Research Institute) (2001) Using ArcGIS geostatistical analyst. ESRI, Redlands, CA

ESRI (Environmental Systems Research Institute) (2006) Using ArcGIS Desktop. ESRI, Redlands, CA

Fretwell SD, Lucas HL Jr (1969) On territorial behavior and other factors influencing habitat distribution in birds. I. Theoretical development. Acta Biotheor 19:16-36

> Fritz RL (1959) Hake tagging in Europe and the United States 1931-1958. J Cons Cons Int Explor Mer 24: 480-485

Fritz RL (1963) An analysis of silver hake tag returns. Int Comm Northwest Atl Fish Spec Publ 4:214-215

> Garrison LP, Link JS (2000) Diets of five hake species in the northeast United States continental shelf ecosystem. Mar Ecol Prog Ser 204:243-255

Grosslein M (1969) Groundfish survey program of BCF Woods Hole. Commer Fish Rev 31:22-30

Hilborn R, Walters CJ (1992) Quantitative fisheries stock assessment: choice dynamics and uncertainty. Chapman \& Hall, New York, NY

> Iles TD, Sinclair M (1982) Atlantic herring: stock discreteness and abundance. Science 215:627-633

> Jakob EM, Marshall SD, Uetz GW (1996) Estimating fitness: a comparison of body condition indices. Oikos 77:61-67

Koeller PA, Coates-Markle L, Neilson JD (1989) Feeding ecology of juvenile (age-0) silver hake (Merluccius bilinearis) on the Scotian Shelf. Can J Fish Aquat Sci 46: 1762-1768

> Kristan III WB (2003) The role of habitat selection behavior in population dynamics: source-sink systems and ecological traps. Oikos 103:457-468

Le Cren E (1951) The length-weight relationship and seasonal cycle in gonad weight and condition in the perch (Perca fluviatilis). J Anim Ecol 20:201-219

Levin PS (1994) Fine-scale temporal variation in recruitment of a temperate demersal fish: the importance of settlement versus post-settlement loss. Oecologia 97: $124-133$ 
Link JS, Lucey SM, Melgey JH (2012) Examining cannibalism in relation to recruitment of silver hake Merluccius bilinearis in the U.S. northwest Atlantic. Fish Res 114: 31-41

Lock M, Packer D (2004) Essential fish habitat source document: silver hake, Merluccius bilinearis, life history and habitat characteristics, 2nd edn. NOAA Tech Memo NMFS-NE 186:82

MacCall AD (1990) Dynamic geography of marine fish populations. University of Washington Press, Seattle, WA

McPeek MA, Rodenhouse NL, Holmes RT, Sherry TW (2001) A general model of site-dependent population regulation: population-level regulation without individual-level interactions. Oikos 94:417-424

Methratta ET, Link JS (2006) Associations between surficial sediments and groundfish distributions in the Gulf of Maine-Georges Bank region. N Am J Fish Manag 26: 473-489

Morse WW (1979) An analysis of maturity observations of 12 groundfish species collected from Cape Hatteras, North Carolina to Nova Scotia in 1977. Sandy Hook Laboratory Report No. SHL 79-32. National Marine Fisheries Service, Washington, DC

Myers RA, Stokes K (1989) Density-dependent habitat utilization of groundfish and the improvement of research surveys. ICES CM 1989/D:15

> Pereira JJ, Schultz ET, Auster PJ (2012) Geospatial analysis of habitat use in yellowtail flounder Limanda ferruginea on Georges Bank. Mar Ecol Prog Ser 468:279-290

Petitgas P (1998) Biomass-dependent dynamics of fish spatial distributions characterized by geostatistical aggrega-

Editorial responsibility: Daniel Dunn, Beaufort, North Carolina, USA tion curves. ICES J Mar Sci 55:443-453

Pulliam HR (1988) Sources, sinks, and population regulation. Am Nat 132:652-661

> Pulliam HR, Danielson BJ (1991) Sources, sinks, and habitat selection: a landscape perspective on population dynamics. Am Nat 137:S50-S66

Rodenhouse NL, Sherry TW, Holmes RT (1997) Site-dependent regulation of population size: a new synthesis. Ecology 78:2025-2042

SAS (2010) SAS/STAT Version 9.3 of the SAS system for Windows. SAS Institute, Cary, NC

Schultz ET, Ludwig M (2005) The essentials on estuarine fish habitat, its evaluation and protection by federal fisheries law. In: Visgilio G, Whitelaw DM (eds) Our changing coast: private rights and public trust. Edward Elgar Publishing, Cheltenham, p 148-167

> Shepherd TD, Litvak MK (2004) Density-dependent habitat selection and the ideal free distribution in marine fish spatial dynamics: considerations and cautions. Fish Fish 5:141-152

Tsou TS, Collie JS (2001) Predation-mediated recruitment in the Georges Bank fish community. ICES J Mar Sci 58: 994-1001

Wilk SJ, Morse WW, Ralph DE, Steady EJ (1976) Life history aspects of Middle Atlantic Bight finfishes (July 1975 to June 1976). Sandy Hook Laboratory Report 76-4, National Marine Fisheries Service, Highlands, NJ

Wilk SJ, Morse WW, Stehlik LL (1990) Annual cycles of gonad-somatic indices as indicators of spawning activity for selected species of finfish collected from the New York Bight. Fish Bull 88:775-786

Submitted: June 10, 2013; Accepted: December 18, 2013

Proofs received from author(s): March 14, 2014 